\title{
Апологетико-просветительские задачи
}

\section{православной теологии в аспекте духовных прозрений Ф.М.Достоевского (к 200-летию со дня рождения писателя)}

\author{
А. А. Лагунов \\ Северо-Кавказский федеральный университет, \\ Российская Федерация, 355017, Ставрополь, ул. Пушкина, 1
}

Для цитирования: Лагунов А. А. Апологетико-просветительские задачи православной теологии в аспекте духовных прозрений Ф. М. Достоевского (к 200-летию со дня рождения писателя) // Вопросы теологии. 2021. Т. 3, № 4. С. 507-516.

https://doi.org/10.21638/spbu28.2021.404

В статье предпринимается попытка определения важнейших задач современной православной теологии посредством анализа духовных прозрений великого русского писателя и философа Ф.М.Достоевского, говорившего о необходимости воспитания русского народа в христианском духе для осуществления им своей всемирной миссии. Российская университетская теология сегодня формируется в условиях мировоззренческо-идеологического и религиозного плюрализма, и дифференциация теологических науки и образования по конфессиональному признаку представляется автору статьи оптимальным решением в сложившейся ситуации. Для православной теологии теоретико-методологическим фундаментом должны стать прежде всего Священное Писание и Священное Предание, богатейший опыт восточного христианства, переданный Древней Руси Византией, святоотеческие творения и труды великого множества блестящих православных богословов, а также духовные и интеллектуальные достижения русских религиозных философов, не без ошибок стремившихся переложить на светский язык богатейшее наследие православной мысли. Анализ литературных произведений, дневников, записных книжек Ф.М.Достоевского, одного из наиболее самобытных представителей русской метафизики, обусловил вывод автора статьи о том, что для современной православной теологии важнейшими задачами являются апологетико-просветительские, направленные на защиту христианской веры от множества сложившихся в период апостасии мифов о ней, на культивирование знаний о православии и о других традиционных для России религиях как у молодежи, так и у старших поколений.

Ключевые слова: Ф.М.Достоевский, народ-богоносец, православная теология, апологетика, религиозное просвещение, русская метафизика, мировоззренческий плюрализм.

(c) Санкт-Петербургский государственный университет, 2021

(c) Общецерковная аспирантура и докторантура им. святых равноапостольных Кирилла и Мефодия, 2021 
Не как мальчик же я верую во Христа и Его исповедую, а через большое горнило сомнений моя осанна прошла.

Ф. М. Достоевский

В советский период отечественной истории теология как научная отрасль и образовательное направление не существовала по идеологическим причинам. Однако ее не было в российских университетах и до революции, и тоже, как представляется, по идеологическим основаниям, хотя несколько иного свойства: сохранялась память о латинском влиянии на духовное образование, в контексте которой риски распространения католических и протестантских теологических ориентаций представлялись весьма высокими. В XVIII в., когда создавались российские университеты, путь в них для теологии был закрыт. Знаменитый историк Русской православной церкви А.В.Карташев верно отмечал: «Откуда было православным взять науку, чтобы не отравиться заразительной латинской и протестантской пищей?» ${ }^{2}$. Лишь в начале XXI в. теология в России наконец приобрела официальный научно-образовательный статус. Однако современность очень сложный феномен с точки зрения мировоззренческого единства, его важнейшим атрибутом является идеологический плюрализм, обусловленный в первую очередь поликонфессиональностью общества, а во вторую - стремительным умножением квазирелигиозных мировоззрений. При этом остается открытым вопрос о том, что же в большей степени влияет на общественное сознание: традиционные или квазирелигиозные картины мира. Разнонаправленные идеологические факторы по-прежнему отрицательно воздействуют на формирующееся теологическое пространство, и вследствие создавшейся мировоззренческо-идеологической ситуации оптимальным стало решение о разделении только что зародившейся российской теологии по конфессиональному признаку. Таким образом, в России оформились три теологии: христианская, исламская и иудейская, - с открытой возможностью формирования и других теологий, как традиционных, имеющих свою историю развития, так и опирающихся на новые религиозные представления. В то же время в рамках этих трех традиционно-религиозных теологий происходит конфессиональное размежевание - так, христианская теология сама по себе не может существовать, по догматическим и богослужебным причинам требуется ее разделение по крайней мере на православную, католическую и протестантскую (точнее, протестантские) теологии, что сегодня и происходит если не де-юре, то де-факто. Дифференциация теологического знания необходима и не может быть преодолена волевым административным решением, поэтому

${ }^{1}$ Цит. по: Новикова-Строганова А. А. Жажда правды и права. Пророчества Ф. М. Достоевского. URL: https://www.pravmir.ru/zhazhda-pravdy-i-prava-prorochestva-f-m-dostoevskogo (дата обращения: 10.07.2021).

${ }^{2}$ Карташев А.В. Очерки по истории Русской церкви: в 2 т. Т. 1. М.: Издательство Сретенского монастыря, 2009. С. 677. 
важнейшей целью дальнейшего направляемого, но не управляемого развития этого знания должна стать координация функций принципиально множащихся теологий, прежде всего функций социальных. Речь должна идти не о догматических спорах между вероисповеданиями, что, как показала история, бессмысленно, а об организации полилога, затрагивающего преимущественно нравственные, аксиологические и культурологические проблемы, а также направленного на поиск общих идеологических ориентиров, без которых невозможно осмысленное и действительно прогрессивное развитие общества.

В данной статье мы обратимся именно к православной теологии, фундирующейся наиболее представленной в нашей стране традиционной религией, сыгравшей «особую роль... в истории России, в становлении и развитии ее духовности и культуры» ${ }^{3}$. Разумеется, как теология православная, она опирается на Священное Писание и Священное Предание, на богатейший опыт восточного христианства, переданный Древней Руси Византией, на святоотеческие творения и труды множества блестящих православных богословов. В ней с необходимостью следует придерживаться строго определенных догматических рамок, которые оставляют достаточно места для свободного богословско-философского поиска; упомянутый выше А. В.Карташев писал об этом так: «Достигнутая степень раскрытия христианской доктрины и ее антично-философская оболочка - не вечны и не единственны. Церковь с угасанием древних культур не состарилась, не омертвела и не утратила присущего ей дара Духа Божия, силы и права при всех переменах и обновлениях умственной жизни человечества непогрешительно устанавливать, если понадобится, и новые формулировки прежних догматов, и принимать новые по языковой и философской форме их истолкования» ${ }^{4}$

На рубеже XIX-XX вв. «перемены и обновления умственной жизни человечества» вызвали становление и развитие такого грандиозного явления, как русская религиозная философия, в считанные десятилетия сделавшая известными всему миру десятки имен мыслителей, представивших оригинальные философско-богословские концепции. Далеко не все русские метафизики считали своим долгом поверять собственные построения двухтысячелетним духовным опытом церкви, однако все они считали себя православными людьми. Объяснить невиданную плодотворность русской религиозной философии можно лишь тем, что она реализовывала творческий потенциал восточного православия, ранее накапливавшийся в разнообразных формах - богословских, богослужебных, иконописных, архитектурных - и выразившийся теперь на понятном для многих интеллектуалов философском языке, воспринятом у Западной Европы. Со-

${ }^{3}$ Федеральный закон от 26.09.1997 № 125-Ф3 «О свободе совести и религиозных объединениях», преамбула. URL: http://www.consultant.ru/document/cons_doc_LAW_16218 (дата обращения: 12.07.2021).

${ }^{4}$ Карташев А. В. Церковь. История. Россия: статьи и выступления. М.: Пробел, 1996. C. 40 . 
временная православная теология должна развивать опыт русской религиозной философии, положив его в свое основание наряду с богатейшим византийско-русским богословским наследием, при этом не повторяя ошибок этого философского направления, заключавшихся в известном дистанцировании многих его представителей от полноты церковной жизни. Однако русская метафизика как философия православно-религиозная дистанцировалась и от «светских» мировоззренческих трендов, в результате чего ее критиковали «и справа, и слева». Во многом поэтому русская религиозная философия, по оценке современного китайского эксперта Чжан Байчуня, трагична, «но в этом и заключена причина успехов русской философии: любая трагедия глубже комедии» ${ }^{5}$.

Каждый из русских религиозных философов по-своему специфичен, заслуживает вдумчивого прочтения и современной интерпретации. Вместе с тем, по нашему мнению, особенного внимания требует наследие Ф.М.Достоевского - и потому, что он не был «профессиональным» философом, облекая свои размышления в литературные формы (хотя только его «Братья Карамазовы», часть неоконченного проекта, стоят многих специально-философских томов), и потому, что многие его философские выводы и духовные прозрения, прошедшие через горнило сомнений, остались если не совсем непонятыми, то недопонятыми и его первыми читателями, и пришедшими им на смену новыми поколениями. Конечно, известными стали некоторые зачастую достаточно вольно трактуемые словесные клише мыслителя, такие как «народ-богоносец», «всебратское единение», «всемирная отзывчивость», «соприкосновение мирам иным», «русская идея» и др. Мы их часто используем, не задумываясь над возможностью раскрытия именно того смысла, который вкладывал в эти слова сам философ, хотя такую задачу чрезвычайно нелегко выполнить.

Например, что имел в виду мыслитель, когда называл русский народ «богоносцем»? То, что он народ избранный и уже по самому факту своего существования «носит» в своих духовных глубинах Бога? Конечно нет, ведь Достоевский устами своего героя вполне ясно говорит: «В тишине воспитайте его...» ${ }^{6}$ Значит, чтобы русскому народу реализоваться в качестве «народа-богоносца», требуется длительный процесс воспитания и просвещения. Причем писатель в этом же месте призывает оберегать сердце народа. Что имел он в виду под «сердцем народа», становится яснее при прочтении строк последнего «Дневника писателя», в которых он говорит о жестокой духовной болезни русского народа, к счастью, не затронувшей еще «главной, мощной сердцевины его души». Болезнь эту Достоевский характеризует как неутоленную жажду правды: «Ищет народ правды и выхода к ней беспрерывно и все не находит...» ${ }^{7}$ Как откры-

5 Чжан Байчунь. О трагедии русской религиозной философии // Вопросы философии. 2007. № 5. С. 79.

${ }^{6}$ Достоевский Ф. М. Братья Карамазовы // Достоевский Ф. М. Полное собрание сочинений: в 30 т. Т. 14. Л.: Наука, 1975. С. 285.

7 Цит. по: Селезнев Ю. И. Достоевский. М.: Молодая гвардия, 1981. С. 535. 
вается из контекста, незатронутым болезнью сердцем народа является не что иное, как православие в его институциональных и мистических (та́инственных) проявлениях. Получается, народ потому и болен, что пытается реализовать свою жажду правды (которая сама по себе болезнью быть не может) вне пространства православного вероисповедания? Очень похоже, что именно это и хотел сказать мыслитель. «В помощь» поиску правды, активизирующемуся неутоленной ее жаждой, пишет он, приходит «бесшабашное пьянство», как море разлившееся в России и свирепствующее в ней, «но все-таки жажды нового, правды новой, правды уже полной народ не утратил, упиваясь даже и вином» ${ }^{8}$.

Достоевский подкрепляет свое духовное прозрение следующим суждением: «Вся глубокая ошибка социалистов в том, что они не признают в русском народе церкви. Я не про здания церковные теперь говорю и не про причты, я про наш русский социализм теперь говорю... Я говорю про неустанную жажду в народе русском всегда в нем присущую, великого, всеобщего, всенародного, всебратского единения... Я желал бы только, чтоб поняли беспристрастно, что я лишь за народ свой стою прежде всего, в его душу, в его великие силы, которых еще никто из нас не знает во всем объеме и величии их, как в святыню верую... И жажду лишь одного: да узрят их все. Только что узрят, тотчас же начнут понимать и все остальное. И почему бы все это мечта?..» ${ }^{9}$ Социалистическая идея превращения «камней в хлебы», разумеется, справедлива, она вполне, хотя и временно, может удовлетворить народную жажду правды, но все дело в том, что она справедлива лишь частично: не затрагивая, казалось бы, сердца народа, она в действительности его разрушает, тем самым уничтожая и сам народ. Русский же социализм, по мысли Достоевского, основывается на «жажде» иного рода, для своего утоления требующей церковного, братского, всеобщего единения, без которого не станет и народа; т. е. люди, конечно, останутся, быть может, они создадут какие-то другие объединения, но именно русского народа уже не будет, поскольку «русский народ весь в православии и в идее его. Более в нем и у него ничего нет - да и не надо, потому что православие всё» ${ }^{10}$.

Жизнь, утверждает писатель, есть «не одно только извлечение квадратного корня» ${ }^{11}$, она не поддается созревающим в «математических головах» схемам общественного переустройства, человечество не может стать «праведным и безгрешным» без длительного «исторического и живого пути» ${ }^{12}$. Достоевский соглашается с тем, что лик нашего мира требует

\footnotetext{
${ }^{8}$ Цит по: Там же.

9 Цит по: Там же. С. 535-536.

${ }^{10}$ Неизданный Достоевский. Записные книжки и тетради 1860-1881 гг. / ред. тома
} И. С. Зильберштейн, Л. М. Розенблюм. М.: Наука, 1971. С. 682. (Литературное наследство. T.83.)

11 Достоевский Ф. М. Записки из подполья // Достоевский Ф. М. Полное собрание сочинений: в 30 т. Т. 5. Л.: Наука, 1973. С. 115.

12 Достоевский Ф. М. Преступление и наказание // Там же. Т. 6. Л.: Наука, 1973. С. 197. 
обновления и возрождения, но для этого нужна не очередная утопия, а напряженная работа, общее дело, идея которого могла бы объединить «всех в единое целое, в нацию, ибо народ, ставший нацией, - духовно взрослый народ; нация - не что иное, как народная личность... Не цивилизацией расцветает народ, но идеей - тогда и цивилизация в пользу пойдет». «Помочь бы народу стать личностью» ${ }^{13}$, - ставит он конкретную задачу. Здесь, на наш взгляд, просматривается прямая параллель с важнейшей задачей формирующейся современной российской православной теологии, причем задачей, выходящей далеко за рамки теологии как образовательного направления, поскольку речь идет даже не о подготовке специалистов, компетентных в соответствующей области, а о просветительской деятельности, не ограничивающейся университетскими пределами. Просветительская задача православной теологии прямо коррелирует с задачей апологетической, так как вследствие долговременной бездеятельности религиозных просветителей вокруг христианства и других традиционных религий сложилось множество мифов, требующих скорейшего развенчания, что представляется необходимым для непосредственной защиты исторических вероисповеданий.

Трудность выполнения православной теологией своих апологетико-просветительских функций обусловливается спецификой современной ситуации: российское общество поликонфессионально, религиозные объединения в нем отделены от государства, а просветительская деятельность регулируется законодательством, к тому же ограничивающим и миссионерскую деятельность, которую всегда при надобности можно связать с просветительской. Так что столь ожидаемого Достоевским православного воспитания русского народа «в тишине», во всяком случае при прямом содействии образовательных организаций, явно не получится. Апологетико-просветительская деятельность православных теологов только может быть переведена в религиоведческую или культурологическую плоскости, но и здесь открывается необъятный простор для творчества. Знания о традиционных религиях у среднестатистического российского школьника или студента, будем честны, отсутствуют, а ведь для того, чтобы реализовать собственный конституционный выбор, исповедовать любую религию или не исповедовать никакой, ему нужно иметь хотя бы смутные представления об исторических вероисповеданиях. Д. В.Шмонин справедливо отмечает: «Теологическое знание не замкнуто на внутрирелигиозной сфере» ${ }^{14}$. Современный православный теолог обязан обладать знаниями не только о христианских конфессиях, но и об основных российских традиционных религиях, и о квазирелигиозных тенденциях «постсекулярного» общества. При выполнении этого условия он будет вполне в состоянии излагать основы истории и вероисповедания наиболее представленных в нашей стра-

${ }^{13}$ Цит. по: Селезнев Ю. И. Достоевский. С. 330.

${ }^{14}$ Шмонин Д. В. Научная рациональность и «возвращение к теологии» // Вопросы теологии. 2019. Т. 1, № 3. С. 298. 
не религий и школьникам, и студентам, т.е. религиозно просвещать их. Личная приверженность определенному вероисповеданию не будет ему мешать, ведь свойственная когда-то многим религиоведам убежденность в том, что только атеистическая позиция мыслителя позволяет объективно и отстраненно исследовать конкретные религии, сегодня серьезно поколеблена: какая может быть объективность, если само атеистическое мировоззрение, по сути квазирелигиозное, дробится на «конфессии».

Достоевский был убежден в силе религиозного просвещения, взывая к своим современникам: «Изучите православие, это не одна только церковность и обрядность, это живое чувство, вполне вот те живые силы, без которых нельзя жить народам» ${ }^{15}$. Христианство, пишет он, является мировоззренческой вершиной человечества, его «величайшей идеей» и «величайшей славой», поскольку представляет собой доказательство того, «что в человеке может вместиться Бог» ${ }^{16}$. Осознав «богом» себя, он уже не может двигаться выше, и всякое новое «достижение» (в рамках сугубо человеческого жизнеустройства) оборачивается теперь его деградацией. Потерю человеком Бога, отсутствие Его в сознании нельзя возместить никакими «общечеловеческими» идеями, даже «любовью к человечеству, потому что человек тотчас спросит: для чего мне любить человечество?»17. Один из героев писателя, старец Зосима, повествует о некоем докторе, «бесспорно умном» и откровенно говорившем: я «люблю человечество, но дивлюсь на себя самого: чем больше я люблю человечество вообще, тем меньше я люблю людей в частности, то есть порознь, как отдельных лиц... Я... становлюсь врагом людей, чуть-чуть лишь те ко мне прикоснутся. Зато всегда так происходило, что чем более я ненавидел людей в частности, тем пламеннее становилась любовь моя к человечеству вообще» ${ }^{18}$. Человечество - только абстракция, и настоящая любовь к нему невозможна, поскольку любовь всегда конкретна, деятельно направлена на ближнего, в котором может присутствовать (точнее, всегда присутствует, даже незамеченным и неосознанным) Бог, - и об этом говорит нам христианство.

Общечеловеческие идеи и ценности становятся легитимными через их религиозное освящение, через придание им объективного характера, и в полной мере это относится к нравственным идеям: «Они вырастают из религиозного чувства, но одной логикой оправдаться никогда не могут... Вы тогда не будете разбиты, когда примете, что нравственные идеи есть (от чувства, от Христа), доказать же, что они нравственны, нельзя (соприкасание мирам иным)» ${ }^{19}$. Добро есть, оно объективно и не зависит от желаний человека, от того, достигнут ли по поводу него консенсус между людьми. Именно поэтому зло всегда остается злом, при любом уровне аргументации в его пользу, а «порочные люди всегда кем-то принуждаемы

\footnotetext{
15 Неизданный Достоевский. С. 570.

16 Там же. С. 616.

17 Там же. С. 610.

18 Достоевский Ф. М. Братья Карамазовы. С. 53.

19 Неизданный Достоевский. С. 695.
} 
говорить, что добродетель все-таки выше, и все-таки молятся добродетели» ${ }^{20}$. И добродетельные, и порочные представители человечества точно знают, когда они поступают безнравственно, поскольку и те, и другие соприкасаются мирам иным. Все мы блуждаем на этой земле, и если бы не было перед нами «драгоценного Христова образа», то мы бы совсем заблудились и погибли: «Многое на земле от нас скрыто, но взамен того даровано нам тайное сокровенное ощущение живой связи нашей с миром иным, с миром горним и высшим, да и корни наших мыслей и чувств не здесь, а в мирах иных» ${ }^{21}$. От сердца человека, в котором борются между собой добро и зло, нужно начинать преобразовательную деятельность, а не от его желудка; лик мира требует обновления и возрождения, но начинать нужно не с мира, даже не с обустроенных в нем людьми социальных институтов, а с самого человека, который может измениться, но не от внешних, а только от внутренних причин, «не иначе как от перемены нравственной». Можно ли достичь этой перемены с помощью оружия, спрашивает Достоевский. «И как сметь сказать заране, прежде опыта, что в этом спасение? И это рискуя всем человечеством. Западная дребедень» 22.

Анализ таких глубоко религиозных убеждений Достоевского ясно показывает всю тщетность и неправомерность использования введенного мыслителем концепта «русской идеи» в качестве националистического. Он призывал русский народ не ограждаться «китайскими стенами» от всего остального человечества, характер его будущей деятельности определял как «в высшей степени общечеловеческий». Русская идея в его представлении может сформироваться, если станет «синтезом всех тех идей, которые с таким упорством, с таким мужеством развивает Европа в отдельных своих национальностях» ${ }^{23}$. Однако нужно полагать, что русская идея может и не сформироваться, если ограждаться «китайскими стенами» и не пытаться синтезировать мировой опыт, а главное - перестать осознавать Бога в себе: «Неверующий деятель у нас в России ничего не сделает, даже будь он искренен сердцем и умом гениален» ${ }^{24}$.

Идеи далеко не всегда спешат реализоваться в действительности, но это не означает, что они совсем на нее не влияют. Достоевский писал: «И сколько же было идей на земле, в истории человеческой, которые даже за десять лет немыслимы были и которые вдруг появлялись, когда приходил для них таинственный срок их, и проносились по всей земле?» 25 . Прошло почти полтора столетия. Многое происходило в российской истории, и хорошего, и дурного, немало пережил русский народ вместе, рука об руку, с другими народами, населяющими шестую часть суши. Можно ли сказать, что идеи самого Достоевского не реализовывались все это
${ }^{20}$ Неизданный Достоевский. С. 558.
${ }^{21}$ Достоевский Ф.М. Братья Карамазовы. С. 290.
${ }^{22}$ Неизданный Достоевский. С. 180.
${ }^{23}$ Цит. по: Гулыга А. В. Русская идея и ее творцы. М.: Эксмо, 2003. С. 13.
24 Достоевский Ф.М. Братья Карамазовы. С. 285.
25 Там же. С. 288. 
время? Наверное, нет: они реализуются, хотя окончательный результат пока, согласимся, плохо виден. Но ведь «окончательный результат» для христианина - это «эсхатон», действительный конец истории падшего человечества, преображение мира и начало совсем новой эры, о которой нам известно очень немногое. Может ли кто-то утверждать, что в том, что нам дан сегодня шанс свободно, без открытых гонений, говорить о православной вере, защищать ее и от нелепых измышлений, и от откровенных нападок, даже вести, основываясь на ней, просветительскую деятельность, нет заслуги Достоевского, как и великого множества других православных мыслителей, мучеников, исповедников и простых, не заметных в суете жизни людей, представителей того именно народа, который следует «воспитать в тишине», чтобы он действительно стал «народом-богоносцем»? Воспитания в тишине не вышло, напротив, фоном для него являлись немыслимые ранее мировые катастрофы ХХ в. Но что имел в виду мыслитель под «тишиной»: уединенное ли и тихое вразумление или же отстраненное сосредоточение духовного опыта, при котором личность осознает свою близость к Богу и тщету всего земного, т.е. чисто человеческого? Наверное, и то, и другое, недаром в романе «Братья Карамазовы» старец Зосима посылает Алешу в мир - нести ему тишину, покой и вразумление.

Статья поступила в редакцию 16 июля 2021 г. Статья рекомендована к печати 1 сентября 2021 г.

Контактная информация:

Лагунов Алексей Александрович - д-р филос. наук, проф.; emaillag@mail.ru

\section{Apologetic and educational tasks of Orthodox theology in regards to F. M. Dostoevsky's spiritual insights (on the occasion of the $200^{\text {th }}$ anniversary of the writer's birth)}

\section{A. A. Lagunov}

North Caucasus Federal University,

1, ul. Pushkina, Stavropol, 355017, Russian Federation

For citation: Lagunov A. A. Apologetic and educational tasks of Orthodox theology in regards to F. M. Dostoevsky's spiritual insights (on the occasion of the $200^{\text {th }}$ anniversary of the writer's birth). Issues of Theology, 2021, vol. 3, no. 4, pp. 507-516.

https://doi.org/10.21638/spbu28.2021.404 (In Russian)

The article attempts to define the most important tasks of modern Orthodox theology by analyzing the spiritual insights of the great Russian writer and philosopher F. M. Dostoevsky. The thinker wrote about the need to educate the Russian people in a Christian spirit in order for them to fulfill their worldwide mission. Russian university theology today is being formed in the conditions of worldview, ideological and religious pluralism. Differentiation of theological science and education on the basis of confessions is optimal in the current situation according to the author of the article. For Orthodox theology, the theoretical and methodological foundation 
should be, first of all, Holy Scripture and Holy Tradition, the richest experience of Eastern Christianity transmitted to Ancient Rus by Byzantium, patristic works and the works of a great many brilliant Orthodox theologians. Also, the spiritual and intellectual achievements of Russian religious philosophers, who, not without mistakes, strove to transfer the richest heritage of Orthodox thought into the secular language should be included. The analysis of Dostoevsky's literary works, diaries, and notebooks, one of the most distinctive representatives of Russian metaphysics, determined the conclusion of the author of the article that for modern Orthodox theology, the most important tasks are apologetic and enlightenment. They are aimed at protecting the Christian faith from the multitude of myths that developed during the period of apostasy. In addition, these tasks are meant to cultivate knowledge about Orthodoxy and other traditional religions for Russia, both among young people and the older generations.

Keywords: F. M.Dostoevsky, Godbearing people, Orthodox theology, apologetics, religious enlightenment, Russian metaphysics, worldview pluralism.

\section{References}

Chzhan Bajchun'. (2007) "On the tragedy of Russian religious philosophy", in Voprosy filosofi, no. 5, pp. 73-79. (In Russian)

Dostoevskii F. M. (1973) "Crime and Punishment", in Dostoevskii F. M. Polnoe sobranie sochinenii. In 30 vols, vol. 6. Leningrad, Nauka Publ. (In Russian)

Dostoevskii F. M. (1975) "Brothers Karamazov", in Dostoevskii F. M. Polnoe sobranie sochinenii. In 30 vols, vol. 14. Leningrad, Nauka Publ. (In Russian)

Dostoevskii F. M. (1973) "Notes from the Underground", in Dostoevskii F. M. Polnoe sobranie sochinenii. In 30 vols, vol. 5. Leningrad, Nauka Publ. (In Russian)

Gulyga A. V. (2003) The Russian idea and its creators. Moscow, Eksmo Publ. (In Russian)

Kartashev A.V. (1996) Church. History of Russia: articles and speeches. Moscow, Probel Publ. (In Russian)

Kartashev A. V. (2009) Essays on the history of the Russian Church. In 2 vols, vol. 1. Moscow, Izdatel'stvo Sretenskogo monastyria Publ. (In Russian)

Novikova-Stroganova A. A. Thirst for truth and right. The prophecies of F. M. Dostoevsky. Available at: https://www.pravmir.ru/zhazhda-pravdy-i-prava-prorochestva-f-m-dostoevskogo (accessed: 10.07.2021). (In Russian)

Seleznev Iu. I. (1981) Dostoevsky. Moscow, Molodaia gvardiia Publ. (In Russian)

Shmonin D. V. (2019) "Scientific rationality and 'return to theology"', in Issues of Theology, vol. 1, no. 3, pp. 280-306. (In Russian)

Zil'bershtein I.S., Rozenblium L.M., eds (1971) Unpublished Dostoevsky. Notebooks and notebooks 1860-1881. Moscow, Nauka Publ. (In Russian)

Received: July 16, 2021

Accepted: September 1, 2021

Author's information:

Aleksey A. Lagunov - Dr. Sci. in Philosophy, Professor; emaillag@mail.ru 